\title{
Predictors of DMSA chelatable lead, tibial lead, and blood lead in 802 Korean lead workers
}

\author{
A C Todd, B-K Lee, G-S Lee, K-D Ahn, E L Moshier, B S Schwartz
}

Department of Community and Preventive Medicine, Mount Sinai School of Medicine, Box 1057, 1

Gustave L Levy Place, New York, NY 10029, USA

A C Todd

E L Moshier

Institute of Industrial Medicine,

Soonchunhyang

University, Chonan,

Korea

B-K Lee

G-S Lee

K-D Ahn

Division of

Occupational and

Environmental Health, Department of Environmental Health

Sciences, Johns

Hopkins School of

Hygiene and Public

Health, Baltimore,

MD, USA

B S Schwartz

Department of

Epidemiology

B S Schwartz

Department of Medicine, Johns Hopkins School of

Medicine

B S Schwartz

Correspondence to: Dr A C Todd

andrew.todd@MSSM.EDU

Accepted 22 September 2000

\begin{abstract}
Objectives-To examine the interrelations among chelatable lead (by dimercaptosuccinic acid, DMSA), tibial lead, and blood lead concentrations in 802 Korean workers with occupational exposure to lead and 135 employed controls with only environmental exposure to lead.
\end{abstract}

Methods-This was a cross sectional study wherein tibial lead, DMSA chelatable lead, and blood lead were measured. Linear regression was used to identify predictors of the three lead biomarkers, evaluating the influence of age, job duration, sex, education level, alcohol and tobacco use, creatinine clearance rate, and body mass index.

Results-DMSA chelatable lead concentrations ranged from 4.8 to $2102.9 \mu \mathrm{g}$ and were positively associated with age, current smoking, and creatinine clearance rate. On average, women had $64 \mu \mathrm{g}$ less DMSA chelatable lead than men. When blood lead and its square were added to a model with age, sex, current smoking, body mass index, and creatinine clearance rate, blood lead accounted for the largest proportion of the variance and sex became of borderline significance. Tibial lead concentrations ranged from -7 to 338 $\mu \mathrm{g} / \mathrm{g}$ bone mineral and were positively associated with age, job duration, and body mass index. Women had, on average, $9.7 \mu \mathrm{g} / \mathrm{g}$ less tibial lead than men. Blood lead concentrations ranged from 4.3 to $85.7 \mu \mathrm{g} / \mathrm{dl}$ and were positively associated with age and tibial lead, whereas current smokers had higher blood lead concentrations and women had lower blood lead concentrations.

Conclusions-The data suggest that age and sex are both predictors of DMSA chelatable lead, blood lead, and tibial lead concentrations and that tibial lead stores in older subjects are less bioavailable and may contribute less to blood lead concentrations than tibial lead stores in younger subjects. Although blood lead concentrations accounted for a large proportion of the variance in DMSA chelatable lead concentrations, suggesting that measurement of both in epidemiological studies may not be necessary, the efficacy of each measure in predicting health outcomes in epidemiological studies awaits further investigation.

(Occup Environ Med 2001;58:73-80)

Keywords: dimercaptosuccinic acid; bone lead; $x$ ray fluorescence
Exposure to lead is most commonly monitored by measuring blood lead concentrations, and, in the United States, the criteria for lead poisoning and lead toxicity are based on blood lead as a standard. However, the biological half life of lead in blood is about 36 days, ${ }^{1}$ and it is therefore an indicator only of recent lead exposure. Blood lead correlates with cumulative dose only if the intensity of exposure has been constant over the working lifetime; this is not generally the case. Moreover, the concentration of lead in blood is a composite index that reflects the equilibrium between current exposure, excretory loss, and the movement of lead between bone and other deep compartments. The relative contribution to the blood lead concentration of each of these sources varies with current exposure and body burden. In one group of currently employed lead workers with varying durations of exposure, the mean endogenous contribution has been estimated to be no more than $10 \%-20 \%^{2}$; whereas, in workers retired after decades of exposure, virtually all the blood lead reflects past exposure..$^{3-5}$ Historical reconstructions of past exposure-for example, the area under the curve of periodic blood lead measurementshave proved useful in some circumstances. ${ }^{6}$ However, they are reliant on the quality of records of past exposure. Thus, they are inherently less accurate than direct biological measurement of body lead burden.

Lead is predominantly stored in the human body in calcified tissues; $90 \%-95 \%$ of the total lead burden is contained within bone in non-occupationally exposed adults, and the total lead content of bone has been reported to be up to $200 \mathrm{mg}$ in $60-70$ year old men, but less in women. ${ }^{78}$ The turnover rate of lead in bone is slow; quantitative estimates of the characteristic half time vary, but there is a consensus that it is of the order of years or even decades. ${ }^{1-11}$ Throughout childhood and most of adult life, lead exposure from both environmental and occupational sources results in an increased lead concentration within the bone matrix. A measure of bone lead content thus reflects integrated or cumulative, and thus long term or chronic exposure to lead. ${ }^{12}$

Bone lead can be measured non-invasively and in vivo by the technique of ${ }^{109} \mathrm{Cd}$ photon induced $\mathrm{K}$ shell energy dispersive $x$ ray fluorescence (XRF). ${ }^{11}{ }^{13} 14$ The $88.034 \mathrm{keV} \gamma$ rays emitted by a ${ }^{109} \mathrm{Cd}$ source are used to excite the lead atoms contained in a person's bone. The lead atoms in the bone de-excite and may thereby emit $x$ rays which are specific to lead. The lead $x$ rays are recorded by a radiation detector, and when compared with calibration data, yield a measure of the lead content of the 
bone. Although the technique delivers a radiation dose to the subject, the radiation dose and consequent risk arising from a ${ }^{109} \mathrm{Cd} \mathrm{K} \mathrm{XRF}$ bone lead measurement are very small for all age groups, including children. ${ }^{15}$

In studies of the health effects of lead, both recent and cumulative dose are estimated, both for the more complete kinetic information they provide and also because recent exposure may be more strongly associated with acute, and thus reversible effects, whereas cumulative exposure may be more strongly associated with chronic, and thus irreversible effects. There is now an array of biological measures available for characterising both exposure-for example, blood lead, chelatable lead, and bone leadand early biological effects-for example, zinc protoporphyrin concentrations in blood or aminolevulinic acid concentrations in plasma or urine. These measures are being examined for their ability to distinguish between acute and chronic health effects of lead.

We report the predictors of three important lead biomarkers in a study with the largest sample size and the highest tibial lead concentrations reported to date.

\section{Methods}

STUDY DESIGN AND OVERVIEW

Our results are a cross sectional analysis of data from the first year (up to 30 July 1999) of a 3 year longitudinal study of the health effects of exposure to inorganic lead in both active and retired employees of 24 different facilities that use lead in the Republic of Korea and in environmentally exposed controls. During the evaluation of each subject in the first year of the study, venous blood was taken to measure whole blood lead, and tibial lead was measured by XRF. Information on demographics, habits, work history, medical history, and medication use was obtained by examiner administered questionnaire. Also, zinc protoporphyrin, urinary aminolevulineic acid, blood urea nitrogen, serum creatinine, haemoglobin, and packed cell volume were measured. Lead workers also provided a 4 hour urine sample after oral administration of dimercaptosuccinic acid (DMSA). The study was reviewed and approved by institutional review boards at the Johns Hopkins School of Hygiene and Public Health and the Soonchunhyang University School of Medicine.

SELECTION OF STUDY SUBJECTS

Participation in the study was voluntary, and all participants provided written, informed consent. Subjects were paid about $\$ 30$ for their participation. Lead workers were recruited from 24 different facilities that use lead, including 11 battery manufacturing plants, six secondary smelting operations, and three lead oxide manufacturing plants. Environmentally exposed controls were recruited from an air conditioner assembly plant that did not use lead or other heavy metals and from among wage earners of Soonchunhyang University.
DATA COLLECTION

Methods of data collection have been described in detail elsewhere. ${ }^{16}$ Briefly, subjects completed standardised medical history and occupational history questionnaires and provided a $10 \mathrm{ml}$ blood specimen by venepuncture for measurement of whole blood lead. Haemoglobin, packed cell volume, urinary creatinine, blood lead, and urinary lead were measured by previously published methods. ${ }^{16-19}$ Ten per cent of the blood lead samples underwent a repeat analysis; the agreement was found to be acceptable. For urinary lead measurements, laboratory protocols for quality control and quality assurance met or exceeded guidelines proposed by the National Committee for Clinical Laboratory Standards for the measurement of lead in urine. ${ }^{20}$ Four hour urinary lead excretion after oral administration of $10 \mathrm{mg} / \mathrm{kg}$ DMSA was used to estimate DMSA chelatable lead (DMSA-Pb). ${ }^{16}$ The validity of the DMSA protocol (dose and urine collection time) is described elsewhere, ${ }^{21-23}$ as is the comparison of $5 \mathrm{mg} / \mathrm{kg}$ and $10 \mathrm{mg} / \mathrm{kg}$ DMSA doses. Controls did not have DMSA chelatable lead measured.

Tibial lead was assessed (in units of $\mu \mathrm{g}$ lead $/ \mathrm{g}$ of bone mineral, hereafter $\mu \mathrm{g} / \mathrm{g}$ ) with a 30 minute measurement of the left mid-tibial diaphysis with ${ }^{109} \mathrm{Cd}$ in a back scatter geometry to fluoresce the $\mathrm{K}$ shell $x$ rays of lead. The lead $x$ rays are recorded with a radiation detector and are then assessed and compared with calibration data to estimate the concentration of lead in bone. ${ }^{1124}$ The emitted $\mathrm{K}$ shell $x$ rays are attenuated as they pass through bone and overlying tissues. The lead $x$ rays are therefore normalised to the amount of elastic scattering from the bone itself to yield a measurement accuracy that is independent of the distance between the radiation source and the subject, subject positioning, small subject movements, overlying tissue thickness, and bone size, shape, geometry, and density. ${ }^{11131424}$ Twenty nine subjects had point tibial lead concentration estimates that were below zero. All point estimates were retained in the statistical analyses, including negative values, because this method minimises bias and does not require censoring of data. ${ }^{25}$

Tibial lead measurements were obtained on $800(99.9 \%)$ of the 802 lead workers. Of the 800 workers who underwent a tibial lead measurement, DMSA chelatable lead was obtained for 787. Most workers who declined to have DMSA chelatable lead measured did so because of concerns about DMSA interfering with their own current medications.

STATISTICAL ANALYSIS

The main goal of the analysis was to identify the predictors of DMSA chelatable lead, tibial lead, and blood lead. Variables examined relative to lead concentrations were sex, education, age, tobacco use, alcohol consumption, body mass index, job duration, and creatinine clearance rate. Height and weight, and their interaction (after each was centred), were considered separately from body mass index. Tibial lead and DMSA chelatable lead were not normally distributed and were therefore (natural $\log$ ) transformed. 
Table 1 Characteristics of 802 current and former lead manufacturing workers and 135 environmentally exposed controls who underwent tibial lead measurement

\begin{tabular}{|c|c|c|c|}
\hline \multirow[b]{2}{*}{ Characteristic } & \multicolumn{3}{|l|}{ Work status } \\
\hline & Active & Retired & Not exposed \\
\hline Number & 723 & 79 & 135 \\
\hline Age (y, median (IQR)) & $39.4(17.8-64.8) 15.6$ & $50.3(35.2-59.1) 8.5$ & $32.3(22.0-60.2) 12.2$ \\
\hline Duration of work with lead (y, median (IQR)) & $6.3(0-36.2) 9.8$ & $8.5(0.5-35.0) 5.7$ & NA \\
\hline \multicolumn{4}{|l|}{ Education (\%): } \\
\hline Less than high school & 45.8 & 86.1 & 19.2 \\
\hline High school & 45.6 & 11.4 & 68.9 \\
\hline Some college & 4.9 & 2.5 & 8.2 \\
\hline Completed college or graduate & 3.7 & 0 & 3.7 \\
\hline \multicolumn{4}{|l|}{ Tobacco use (\%): } \\
\hline Never & 27.0 & 76.0 & 25.9 \\
\hline Current & 61.1 & 20.2 & 64.4 \\
\hline Past & 11.9 & 3.8 & 9.6 \\
\hline \multicolumn{4}{|l|}{ Alcohol use (\%): } \\
\hline Never & 26.2 & 54.4 & 23.0 \\
\hline Current & 67.7 & 40.5 & 70.4 \\
\hline Past & 6.1 & 5.1 & 6.7 \\
\hline Height (cm, mean (SD)) & $165.5(7.8)$ & $157.3(7.6)$ & $167.9(6.2)$ \\
\hline Weight $(\mathrm{kg}$, mean (SD)) & $62.8(9.2)$ & $59.6(7.7)$ & $66.9(9.0)$ \\
\hline Body mass index $\left(\mathrm{kg} / \mathrm{m}^{2}\right.$, mean $\left.(\mathrm{SD})\right)$ & $23(3)$ & $24(3)$ & $24(3)$ \\
\hline Tibia lead ( $\mu \mathrm{g} / \mathrm{g}$, median (range) IQR) & $24.4(-7.4$ to 337.6$) 35.2$ & $26.4(-6.7$ to 196.7$) 24.3$ & $5.0(-10.9$ to 26.6$) 8.4$ \\
\hline Tibia lead measurement error $(\mu \mathrm{g} / \mathrm{g}$, median (IQR)) & $4.8(0.6-15.8) 2.0$ & $5.3(3.0-10.8) 3.4$ & $6.3(5.0-12.0) 0.9$ \\
\hline DMSA chelatable lead ( $\mu \mathrm{g}$, median (IQR)) & $129.9(4.8-2102.9) 202.4$ & $37.4(4.8-508.0) 50.5$ & NA \\
\hline Blood lead ( $\mu \mathrm{g} / \mathrm{dl}$, median (IQR)) & $31.7(5.4-85.7) 19.3$ & $13.5(4.3-47.8) 11.1$ & $5.1(2.0-10.0) 2.6$ \\
\hline Creatinine clearance rate $(\mathrm{ml} / \mathrm{min}$, mean $(\mathrm{SD}))$ & $96.4(25.9)$ & $116.3(34.1)$ & NA \\
\hline
\end{tabular}

$\mathrm{NA}=$ not applicable; $\mathrm{IQR}=$ interquartile range.

Multiple linear regression with SAS (SAS Institute, Carey, NC, USA) was used to model DMSA chelatable lead, tibial lead, and blood lead, controlling for such variables as age, and tobacco and alcohol consumption. No preselection of variables was performed, ${ }^{26}$ and both stepwise and backwards elimination methods were compared. All linear regression models were evaluated for the influence of outliers, multicolinearity and departures from normality, and heteroscedasticity. No two variables had proportions of variance exceeding 0.5 on a principal component having a condition index larger than $35 .^{27}$ To examine non-linear effects, linear and quadratic terms were evaluated for continuous variables. All continuous variables were centred before entry into linear regression models when used for non-linear and interaction terms. Partial residual plots were used to examine final regression models for linearity and influential points. The assumption of homoscedasticity was confirmed by plotting residuals against predicted values. There were no points of undue influence and no evidence of heteroscedasticity in the final models.

In analyses with lead biomarkers, only current $(90 \%)$ or former $(10 \%)$ lead workers were included in the models. Linear regression modelling of tibial lead was performed for both weighted (by the inverse of the square of the measurement error) and unweighted tibial lead values; weighted model results were not conceptually different from unweighted models, and unweighted models are therefore presented. Because of incomplete data, models of DMSA chelatable lead, tibial lead, and blood lead were developed from 779, 796, and 800 current or former lead workers, respectively.

\section{Results}

ENVIRONMENTALLY EXPOSED CONTROLS

The environmentally exposed controls were $91.9 \%$ male, and $80.7 \%$ of them had been educated to high school graduation or beyond (table 1). They were exclusively Korean and had a mean (SD, range) age of $34.5(9.1,22$ to 60) years. Their mean (SD, range) tibial lead concentration was $5.8(7.0,-11$ to 27$) \mu \mathrm{g} / \mathrm{g}$, and their mean blood lead concentration was $5.3(1.8,2$ to 10$) \mu \mathrm{g} / \mathrm{dl}$.

Sex, height, and weight (or body mass index), smoking, drinking, age, and blood lead concentrations were considered for inclusion in the regression models for environmentally exposed subjects. Multiple linear regression modelling showed that only sex predicted (ln transformed) tibial lead concentration, with women having higher bone lead concentrations than men $\left(\beta\left(\mathrm{SE}_{\beta}\right)=0.3(0.1) \mu \mathrm{g} / \mathrm{g} ; \mathrm{p}=0.003\right)$. The final model accounted for only $4 \%$ of the observed variability in tibial lead concentrations. Blood lead concentrations for the environmentally exposed controls did not require transformation and were found to increase with age $\left(\beta \quad\left(\mathrm{SE}_{\beta}\right)=0.038 \quad(0.016)\right.$ $(\mu \mathrm{g} / \mathrm{dl}) / \mathrm{y} ; \mathrm{p}=0.02)$. Women had lower blood lead concentrations $\left(\beta\left(\mathrm{SE}_{\beta}\right)=-2.7(0.6) \mu \mathrm{g} / \mathrm{dl}\right.$; $\mathrm{p}<0.001$ ) by contrast with their higher tibial lead concentrations, and those who had never smoked also had lower blood lead concentrations $\left(\beta\left(\mathrm{SE}_{\beta}\right)=-0.79(0.36) \mu \mathrm{g} / \mathrm{dl} ; \mathrm{p}=0.03\right)$. The final model accounted for $23 \%$ of the observed variability in blood lead concentrations.

OCCUPATIONALLY EXPOSED WORKERS

The lead workers who had tibial lead measurements were $79.5 \%$ men, and $50.1 \%$ of them had been educated to high school level or beyond (table 1). They too were exclusively Korean and had a mean (SD, range) age of 40.5 (10.1, 17.8 to 64.8 ) years and a mean (SD, range) job duration of 8.2 (6.5, 0.1 to $36.2)$ years. DMSA chelatable lead concentrations ranged from 4.8 to $1169.6 \mu \mathrm{g}$ (after deleting four outliers), with a mean (SD) of 178.0 (177.3) $\mu \mathrm{g}$; tibial lead concentrations ranged from -7 to $338 \mu \mathrm{g} / \mathrm{g}$, with a mean (SD) 
Table 2 Linear regression modelling results identifying predictors of (In transformed) DMSA chelatable lead concentrations in 779 Korean lead workers

\begin{tabular}{lcc}
\hline Independent variables (units of $\beta$ coefficient) & $\beta$ coefficient (SEM) & $p$ Value \\
\hline Model 1: without blood lead (adjusted $\left.r^{2} 25.3 \%\right):$ & $2.438(0.301)$ & $<0.001$ \\
Intercept & $0.033(0.003)$ & $<0.001$ \\
Age $\left(\mu \mathrm{g}^{\star} / \mathrm{y}\right)$ & $-0.914(0.103)$ & $<0.001$ \\
Female $(\mu \mathrm{g})^{\star}$ & $0.325(0.079)$ & $<0.001$ \\
Current smoker $(\mu \mathrm{g})^{\star}$ & $0.014(0.011)$ & 0.22 \\
Body mass index $\left(\mu \mathrm{g}^{\star} /\left(\mathrm{kg} / \mathrm{m}^{2}\right)\right)$ & $0.005(0.001)$ & $<0.001$ \\
Creatinine clearance rate $\left(\mu \mathrm{g}^{\star} /(\mathrm{ml} / \mathrm{min})\right)$ & & $<0.001$ \\
Model 2: with blood lead $\left(\mathrm{adjusted} r^{2} 81.6 \%\right):$ & $3.499(0.151)$ & $<0.001$ \\
Intercept & $0.007(0.002)$ & 0.065 \\
Age $\left(\mu \mathrm{g}^{\star} / \mathrm{y}\right)$ & $0.102(0.055)$ & $<0.001$ \\
Female $(\mu \mathrm{g})^{\star}$ & $0.134(0.039)$ & $<0.001$ \\
Current smoker $(\mu \mathrm{g})^{\star}$ & $0.019(0.006)$ & $<0.001$ \\
Body mass index $\left(\mu \mathrm{g}^{\star} /\left(\mathrm{kg} / \mathrm{m}^{2}\right)\right)$ & $0.005(0.0005)$ & $<0.001$ \\
Creatinine clearance $\mathrm{rate}\left(\mu \mathrm{g}^{\star} /(\mathrm{ml} / \mathrm{min})\right)$ & $0.064(0.001)$ & $<0.001$ \\
Blood lead $\left(\mu \mathrm{g}^{\star} /(\mu \mathrm{g} / \mathrm{dl})\right)$ & $-6.6 \times 10^{-4}\left(0.6 \times 10^{-4}\right)$ & \\
Blood lead squared $\left(\mu \mathrm{g}^{\star} /(\mu \mathrm{g} / \mathrm{dl})^{2}\right) \dagger$ & & \\
\hline
\end{tabular}

${ }^{\star} \mu \mathrm{g}$ DMSA chelatable lead on the natural logarithm scale.

†To account for non-linear associations.
PREDICTORS OF CHELATABLE LEAD

CONCENTRATIONS

After four outliers were excluded, age and creatinine clearance rate were both found to be independent, positive predictors of DMSA chelatable lead (table 2). Body mass index was forced into the model, as weight was used to determine DMSA dose, ${ }^{21}$ but was not found to be a significant predictor. Non-smoking women of average age ( 40.35 years), creatinine clearance rate $(114.26 \mathrm{ml} / \mathrm{min})$, and body mass index $\left(23.01 \mathrm{~kg} / \mathrm{m}^{2}\right)$ had, on average, $63.5 \mu \mathrm{g}$ less chelatable lead than men $(p<0.001)$, and male current smokers of average age (40.35 years), creatinine clearance rate $(114.26 \mathrm{ml} /$ $\mathrm{min})$, and body mass index $\left(23.01 \mathrm{~kg} / \mathrm{m}^{2}\right)$ had, on average, $40.7 \mu \mathrm{g}$ more chelatable lead than subjects who were ex-smokers or who had never smoked $(\mathrm{p}<0.001)$.

When both linear and quadratic blood lead terms were allowed to enter the model, sex became of borderline significance $(p=0.065)$, but body mass index became significant. Male smokers of average age (40.35 years), creatinine clearance rate $(114.26 \mathrm{ml} / \mathrm{min})$, body mass index $\left(23.01 \mathrm{~kg} / \mathrm{m}^{2}\right)$, and blood lead $(31.52 \mu \mathrm{g} / \mathrm{dl}) \mathrm{had}$, on average, $14.6 \mu \mathrm{g}$ more chelatable lead than subjects who were exsmokers or who had never smoked $(p<0.001)$. Both linear and quadratic blood lead terms (of opposite sign) were significant, indicating nonlinearity in the chelatable lead/blood lead relation (fig 1). Blood lead accounted for most of the variability found in DMSA chelatable lead $r=0.87, \mathrm{p}<0.001$ ) concentrations.

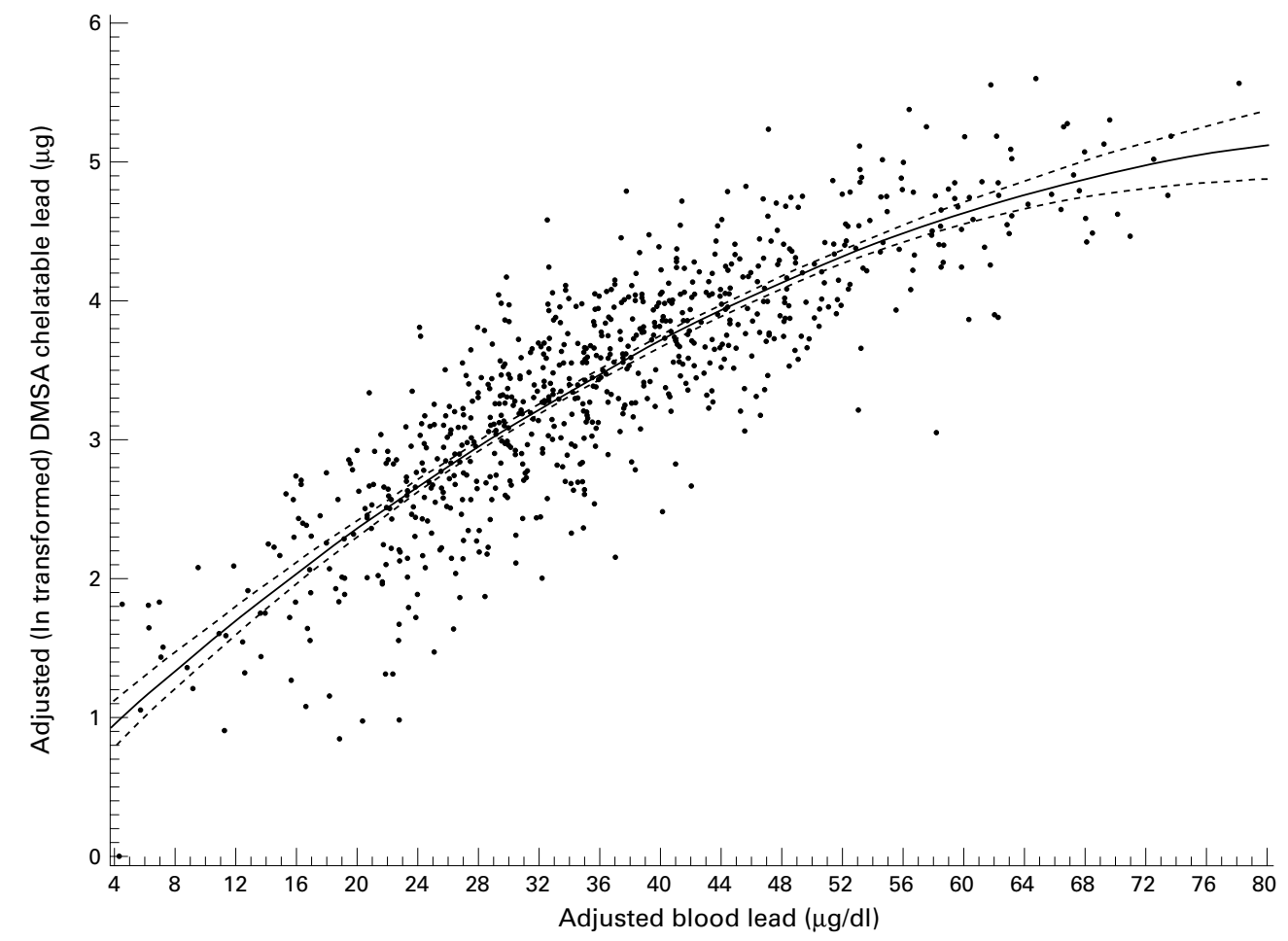

Figure 1 The residuals from the regression of In transformed DMSA chelatable lead on age, sex, body mass index, current smoking, and creatinine clearance rate plus the minimum residual value $v$ the residuals from the regression of blood lead concentrations on age, sex, body mass index, current smoking, and creatinine clearance rate plus the minimum residual value in 779 active and retired lead workers with past and current exposure to lead. Dashed lines represent 95\% confidence intervals on either side of the linear regression line. Addition of a quadratic term for blood lead significantly improved the relation with DMSA chelatable lead concentrations. 


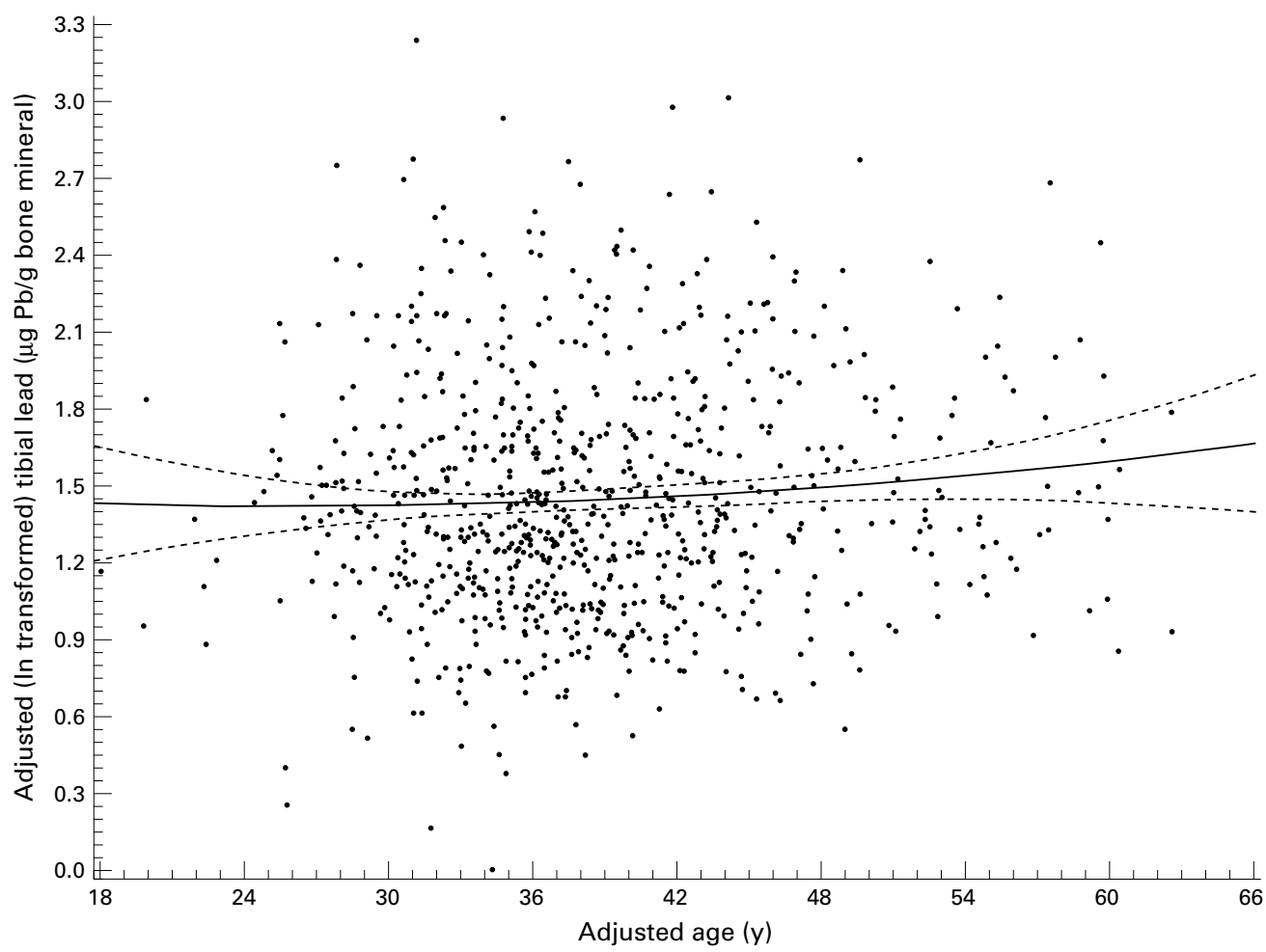

Figure 2 The residuals from the regression of In transformed tibial lead on job duration, sex, height, and body mass index plus the minimum residual value $v$ the residuals from the regression of age on job duration, sex, height, and body mass index plus the minimum residual value, in 796 active and retired lead workers. Dashed lines represent $95 \%$ confidence intervals. on either side of the linear regression line. Addition of a quadratic term for age significantly improved the relation with tibial lead concentrations.

concentrations $(56 \%)$, and the proportion of the variability accounted for increased to $81.6 \%$ in the final model.

PREDICTORS OF TIBIAL LEAD

Job duration (fig 2) and body mass index $\left(\mathrm{kg} / \mathrm{m}^{2}\right)$ were both found to be independent, positive predictors of tibial lead concentrations. Age was also found to be an independent positive predictor of tibial lead concentrations, but tibial lead concentrations increased with age in a non-linear manner that required the addition of a quadratic age term (fig 3 and table 3). The $\beta$ coefficients of both age and age squared were positive-that is, the rate of increase of tibial lead with age itself increased with increasing age. Women of average age (40.46 years), job duration (8.21 years), and body mass index $\left(23.01 \mathrm{~kg} / \mathrm{m}^{2}\right)$ had, on average, $9.7 \mu \mathrm{g} / \mathrm{g}$ less tibial lead than men $(\mathrm{p}<0.001)$.

Current or past tobacco use were not significant predictors of tibial lead; neither were education level, drinking, or creatinine clearance rate, all of which were evaluated for their influence on tibial lead concentrations (as were squared terms for the continuous variables). The final model, with five variables (age, age squared, sex, job duration, and body mass index) accounted for $18.8 \%$ of the variability found in the tibial lead concentrations.

PREDICTORS OF BLOOD LEAD

Blood lead concentrations increased with age and increased, in a non-linear manner, with tibial lead concentrations (fig 3 and table 4).
The fitted quadratic form is not a result of the few large tibial lead concentrations or the tail in the distribution of tibial lead values. The $\beta$ coefficients of tibial lead and tibial lead squared were of opposite sign, indicating that the rate of increase in the contribution of bone lead stores to blood lead concentrations decreases with increasing bone lead stores. After adjusting for age, sex, tibial lead, and tibial lead squared, current smokers had, on average, blood lead concentrations that were $2.9 \mu \mathrm{g} / \mathrm{dl}$ lower than those of subjects who were ex-smokers or who had never smoked. After adjusting for age, smoking, tibial lead, and tibial lead squared, women had, on average, blood lead concentrations that were $13.7 \mu \mathrm{g} / \mathrm{dl}$ lower than those of men.

\section{Discussion}

The environmentally exposed controls in this study had tibial lead concentrations (mean (SD) of $5.8(7.0) \mu \mathrm{g} / \mathrm{g}$ ) that were significantly lower $(p<0.01)$ than those found in a study of 116 47-59 year old environmentally exposed United States men (mean (SD) $15(8) \mu \mathrm{g} / \mathrm{g}$ ). ${ }^{28}$ It is therefore possible that past environmental exposures in the United States exceeded those in the Korean environmentally exposed controls, resulting in the higher bone lead concentrations in the United States subjects. However, the Korean environmentally exposed controls were also younger than the United States subjects, and this may account for some of the difference. The tibial lead concentrations of Korean environmentally exposed controls were within the range found in active and 


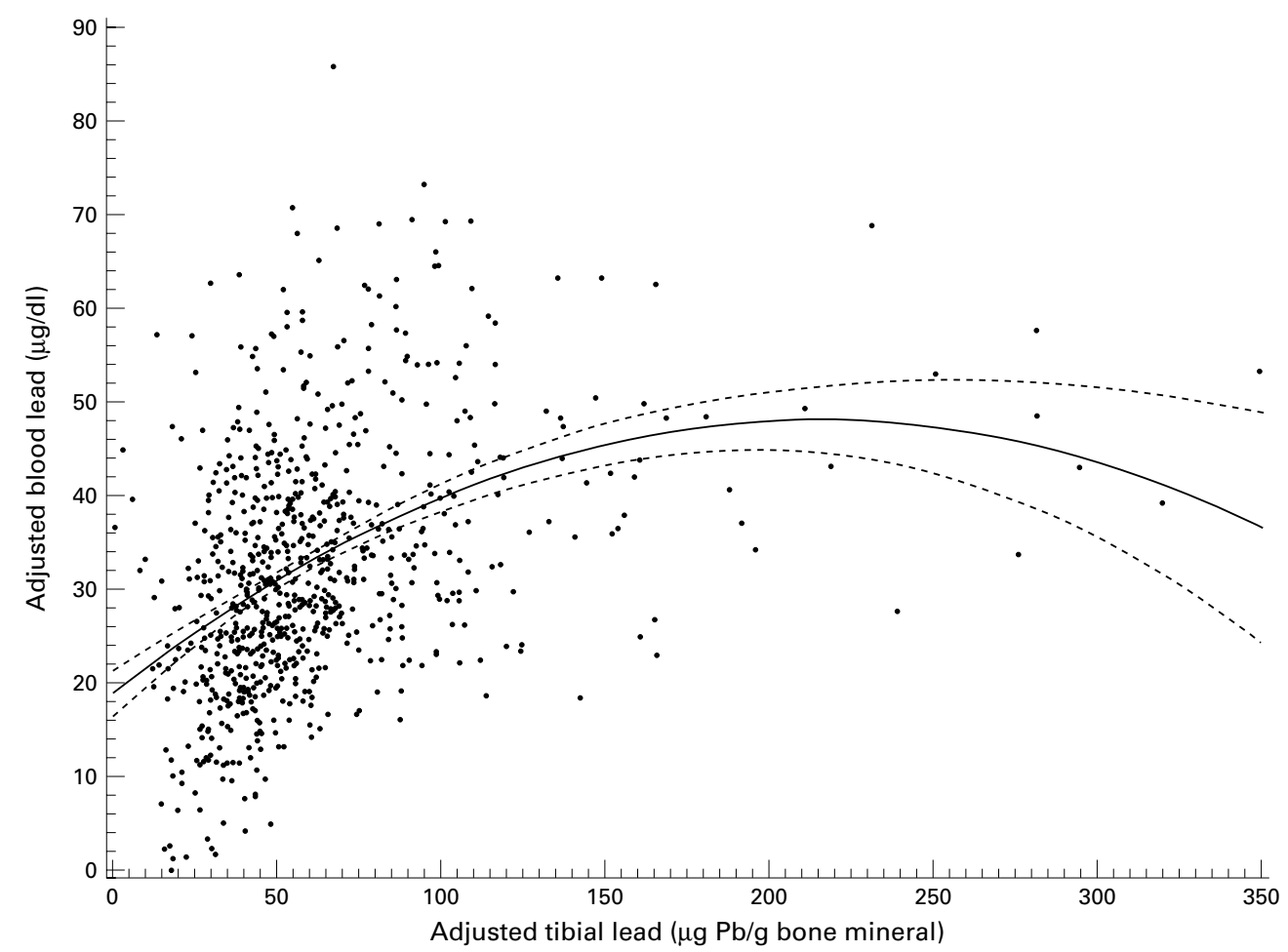

Figure 3 The residuals from the regression of blood lead on age, sex and current smoking plus the minimum residual value $v$ the residuals from the regression of tibial lead on age, sex, and current smoking plus the minimum residual value in 800 active and retired lead workers. Dashed lines represent $95 \%$ confidence intervals on either side of the linear regression line. Addition of a quadratic term for tibial lead significantly improved the relation with blood lead concentrations.

retired lorry assembly workers in Sweden. ${ }^{10}$ By contrast with the bone lead results, the environmentally exposed Korean controls had blood lead concentrations (mean (SD) of 5.3 (1.8) $\mu \mathrm{g} / \mathrm{dl}$ ) that were significantly greater $(\mathrm{p}<0.05)$ than those found in a study of 13642 people aged 1 year or older (geometric mean $2.3 \mu \mathrm{g} / \mathrm{dl}) .^{29}$ This suggests that the United States population presently experiences lower concentrations of lead exposure than their Korean counterparts.

In the workers exposed to lead in this study, mean DMSA chelatable lead, tibial lead, and blood lead concentrations were all high. We are unaware of previous studies that have evaluated

Table 3 Linear regression modelling results identifying predictors of (In transformed) tibial lead concentrations in 796 Korean lead workers (model adjusted $r^{2} 18.8 \%$ )

\begin{tabular}{lcr}
\hline Independent variables (units of $\beta$ coefficient) & $\beta$ coefficient $($ SEM) & $p$ Value \\
\hline Intercept & $3.248(0.136)$ & $<0.001$ \\
Age $((\mu \mathrm{g} / \mathrm{g}) / \mathrm{y}) \dagger$ & $0.006(0.002)$ & 0.006 \\
Age squared $\left((\mu \mathrm{g} / \mathrm{g}) / \mathrm{y}^{2}\right)^{\star} \dagger$ & $0.0006(0.0002)$ & $<0.001$ \\
Female $(\mu \mathrm{g} / \mathrm{g}) \dagger$ & $-0.212(0.048)$ & $<0.001$ \\
Job duration $((\mu \mathrm{g} / \mathrm{g}) / \mathrm{y}) \dagger$ & $0.028(0.003)$ & $<0.001$ \\
Body mass index $\left((\mu \mathrm{g} / \mathrm{g}) /\left(\mathrm{kg} / \mathrm{m}^{2}\right)\right) \dagger$ & $0.017(0.006)$ & 0.004 \\
\hline
\end{tabular}

^To account for non-linear associations.

† $\mathrm{g}$ Lead/g bone mineral on the natural logarithm scale.

Table 4 Linear regression modelling results identifying predictors of blood lead concentrations in 800 Korean lead workers (model adjusted $r^{2} 36.5 \%$ )

\begin{tabular}{lcr}
\hline Independent variables (units of $\beta$ coefficient) & $\beta$ coefficient $($ SEM) & $p$ Value \\
\hline Intercept $(\mu \mathrm{g} / \mathrm{dl})$ & $23.242(2.170)$ & $<0.001$ \\
Age $(\mu \mathrm{g} / \mathrm{dl} / \mathrm{y})$ & $0.272(0.048)$ & $<0.001$ \\
Female $(\mu \mathrm{g} / \mathrm{dl})$ & $-13.658(1.136)$ & $<0.001$ \\
Current $\mathrm{smoker}(\mu \mathrm{g} / \mathrm{dl})$ & $2.931(1.063)$ & 0.006 \\
Tibia lead $(\mu \mathrm{g} / \mathrm{dl} /(\mu \mathrm{g} / \mathrm{g}))$ & $0.214(0.018)$ & $<0.001$ \\
Tibia lead squared $\left(\mu \mathrm{g} / \mathrm{dl} /(\mu \mathrm{g} / \mathrm{g})^{2}\right)^{\star}$ & $-6.95 \times 10^{-4}\left(1.1 \times 10^{-4}\right)$ & $<0.001$ \\
\hline
\end{tabular}

^To account for non-linear associations.
DMSA chelatable lead or tibial lead concentrations in so many workers.

In this large, cross sectional study of 802 manufacturing workers, tibial lead and blood lead were identified as two independent predictors of DMSA chelatable lead. Age was a significant positive predictor of all three lead biomarkers and being female was a significant negative predictor of all three lead biomarkers. Current smoking was positively associated with both blood and DMSA chelatable lead, and women had significantly lower bone lead and blood lead concentrations. Women also had significantly lower DMSA chelatable lead concentrations when blood lead was excluded from the model. However, when blood lead was used to model DMSA chelatable lead, women had higher chelatable lead concentrations than men of the same age, smoking habit, body mass index, creatinine clearance rate, and blood lead concentration, but the difference was much smaller and the effect did not quite reach significance. It seems likely that the women in this group have less exposure to lead than the men. If DMSA chelatable lead can be thought of as bioavailable lead, then this finding may have public health implications for the hypothesis of mobilisation of skeletal lead during periods of high bone turnover such as pregnancy and lactation.

When blood lead was allowed to model DMSA chelatable lead, both linear and quadratic blood lead terms proved to be predictive but were of opposite sign, indicating that the DMSA chelatable lead reaches a plateau at higher blood lead concentrations. The final 
regression model for chelatable lead accounted for only a quarter of the variability found without blood lead in the model, but about $80 \%$ if blood lead were allowed into the model. By contrast, the final regression model for tibia accounted for only $19 \%$ of the variability found in tibial lead. Although some of the unexplained variance in tibial lead may be accounted for by measurement error in predictor variables and in the XRF measurement of tibial lead, it is also possible that variability between metabolic mediators of lead metabolism of individual workers may also account for some of the unexplained variance.

The current study has considerably more power than previous studies ${ }^{2123}{ }^{30}$ and identifies several independent predictors of DMSA chelatable lead concentrations. In previous studies, cumulative smoking and weight have been identified as predictors of DMSA chelatable lead concentrations. However, in this study cumulative smoking did not prove to be predictive, and body mass index (used in place of weight) was significant only when blood lead was used to model DMSA chelatable lead. Current smokers did have higher DMSA chelatable lead concentrations both in the present study and in our previous study. ${ }^{21}$ The two studies also agree that bone lead stores are not found to be predictive of DMSA chelatable lead (when blood lead was allowed in the model in the previous study). This study is also consistent with the previous studies in showing that job duration is not a significant predictor of DMSA chelatable lead concentrations. ${ }^{23} 30$

It was expected that job duration would be a significant predictor of tibial lead, and this proved to be so. Body mass index was also a significant, positive predictor of tibial lead; heavier or shorter subjects had higher tibial lead concentrations. Only one previous study ${ }^{21}$ found an association between tibial lead and an anthropometric measure; taller subjects had lower bone lead. The two findings are not entirely consistent but would not be expected to be, as the previous study was one of older, retired workers with past exposure to both inorganic and organic lead, whereas the present study is one of younger workers with current exposure to inorganic lead only. Further study of a similarly large group of workers would help to clarify the situation.

Age is often identified as a significant predictor of tibial lead in environmentally exposed controls both in XRF based studies ${ }^{31-34}$ and in studies where bone lead concentrations are assessed by chemical means. ${ }^{7-9} \mathrm{Hu}$ recently suggested that such associations are a cohort effect in these cross sectional studies. ${ }^{35}$ Both explanations may have validity, but it is likely that the ability to find an association between bone lead and age may be as dependent on the concentration, duration, and time dependence of the environmental exposure as is the association between bone lead and blood lead. Our data suggest that, for these workers, their tibial lead increases with age even after adjustment for job duration. We therefore think that it is likely that bone lead does indeed increase with age, even at the lower concentrations of exposure currently prevalent in the United States.

Bone lead can act as an endogenous source of exposure to lead, elevating blood lead concentrations; workers with greater exposure have higher tibial lead concentrations and consequently higher blood lead concentrations. In this study, we found that both tibial lead and tibial lead squared were independent predictors of blood lead, but that the parameter estimates for the two terms were of opposite sign. This indicates that the contribution of the lead in the tibia to the amount of lead in the blood reaches a maximum. This could be because of the dynamics of exchange between slowly exchangeable and more rapidly exchangeable pools of bone lead. As the workers with higher bone leads also tend to be older workers, it is also possible that the tibial lead stores are less bioavailable for endogenous increase of blood lead concentrations in the older workers. This suggestion is consistent with previous data that also suggested that the fraction of lead stores that is bioavailable decreases with increasing age. $^{21}$

Tibial lead concentrations are a measure of lifetime retained lead burden, reflecting both cumulative lead exposure and the influence of excretory pathways that eliminate lead from bone with an estimated half life of 10-15 years. ${ }^{136}$ By contrast, DMSA chelatable lead concentrations are thought to reflect current bioavailable lead burden, ${ }^{23}{ }^{30}$ removing lead principally from blood and soft tissue and minimally, if at all, from bone. ${ }^{30} 37$ The finding that job duration predicts tibial lead concentrations but not chelatable lead concentrations supports the notions that the tibial lead reflects cumulative exposure and that DMSA chelatable lead reflects current bioavailable lead stores. In epidemiological studies, it may not be necessary to measure both blood lead and DMSA chelatable lead, as they both measure currently bioavailable lead stores. However, it is possible that DMSA chelatable lead may be a better predictor of one or more acute health outcomes and therefore be the more useful of the two measures under certain circumstances. Further work is required if this question is to be answered. The therapeutic value of DMSA is, of course, unaffected by our findings.

In conclusion, the data from this group of workers show that there are common predictors for DMSA chelatable lead, tibial lead, and blood lead (age and sex) and that a substantial amount of the variance in DMSA chelatable lead can be explained by blood lead. Tibial lead increases with age, independently of job duration, and the endogenous contribution of tibial lead to blood lead is non-linear and reaches a maximum.

We thank D Simon for invaluable statistical assistance. This research was supported by grant R01 ES07198 from the National Institute of Environmental Health Sciences (NIEHS).

\footnotetext{
1 Rabinowitz M, Wetherill G, Kopple J. Kinetic analysis of lead metabolism in healthy humans. 7 Clin Invest lead metabolism

Tell I, Somervaille L, Nilsson U, et al. Chelated lead and bone lead. Scand $\mathcal{F}$ Work Environ Health 1992;18:113-19.
} 
3 Christoffersson J-O, Schütz A, Ahlgren L, et al. Lead in finger-bone analysed in vivo in active and retired lead finger-bone analysed in vivo in active
workers. Am $\mathcal{F}$ Ind Med 1984;6:447-57.

4 Schütz A, Skerfving S, Christoffersson J-O, et al. Lead in vertebral bone biopsies from active and retired workers. Arch Environ Health 1987;42:340-6.

5 Skerfving S, Christoffersson J-O, Schütz A, et al. Biological monitoring, by in vivo XRF measurements, of occupational exposure to lead, cadmium, and mercury. Biol Trace Elem Res 1987;13:241-51.

6 Roels H, Konings J, Green S, et al. Time-integrated blood lead concentration is a valid surrogate for estimating the cumulative lead dose assessed by tibial lead measurement. Environ Res 1995;69:75-82.

7 Barry P. A comparison of concentrations of lead in human tissues. Br f Ind Med 1975;32:119-39.

8 Barry P, Mossman D. Lead concentrations in human tissues. Br F Ind Med 1970;27:339-51.

9 Wittmers LJr, Wallgren J, Alich A, et al. Lead in bone. IV. Distribution of lead in the human skeleton. Arch Environ Distribution of lead in
Health $1988 ; 43: 381-91$

10 Gerhardsson L, Attewell R, Chettle D, et al. In vivo measurements of lead in bone in long-term exposed lead

11 Todd A, Chettle D. In vivo $x$ ray fluorescence of lead in bone: review and current issues. Environ Health Perspect 1994;102:172-7.

12 Somervaille L, Chettle D, Scott M, et al. In vivo tibia lead measurements as an index of cumula pationally exposed subjects. Br f Ind Med 1988;45:174-81.

13 Todd A. Contamination of in vivo bone-lead measurements. Phys Med Biol 2000;45:229-40.

14 Todd A. Calculating bone-lead measurement variance. Environ Health Perspect 2000;108:383-6.

15 Todd $\mathrm{A}, \mathrm{McNeill} \mathrm{F}$, Palethorpe J, et al. In vivo $x$ ray fluorescence of lead in bone using $\mathrm{K} x$ ray excitation with ${ }^{109} \mathrm{Cd}$ sources: radiation dosimetry studies. Environ Res 1992;57: sources:

16 Schwartz B, Lee B, Lee G, et al. Associations of blood lead, DMSA chelatable lead and tibial lead with neurobehavDMSA chelatable lead and tibial lead with neurobehav2000.

17 Parsons P, Slavin W. Electrothermal atomization atomic absorption spectrometry for the determination of lead in urine: results of an interlaboratory study. Spectrochim Acta Part B 1999;54:853-64.

18 Thomas W, Collins T. Comparison of venipuncture blood counts with microcapillary measurements in screening for anemia in 1 year old infant. $\mathcal{F}$ Pediatr $1982 ; 101: 32-5$.

19 Heinegard D, Tiderstrom G. Determination of serum creatinine by a direct colorimetric method. Clin Chem Acta 1973;43:305

20 National Committee for Clinical Laboratory Standards (NCCLS). Analytical procedures for the determination of lead in blood and urine; proposed guideline. Wayne, PA: NCCLS, 1998 .
21 Schwartz B, Stewart W, Todd A, et al. Predictors of dimercaptosuccinic acid chelatable lead levels and tibial lead levels in organolead manufacturing workers. Occup Environ Med 1999;56:22-9.

22 Schwartz B, Stewart W, Todd A, et al. Different associations of blood lead, meso 2,3-dimercaptosuccinic acid (DMSA) chelatable lead, and tibial lead levels with blood pressure in 543 former organolead manufacturing workers. Arch Environ Health 2000;55:85-92.

23 Lee B, Schwartz B, Stewart W, et al. Urinary lead excretion after DMSA and EDTA: evidence for differential access to lead storage sites. Occup Environ Med 1995;52:13-19.

24 Todd A, McNeill F. In vivo measurements of lead in bone using a ${ }^{109} \mathrm{Cd}$ "spot" source. In: Ellis K, Eastman J, eds. Human body composition studies. New York: Plenum Press, 1993:299-302.

25 Troyer G, Jones R, Jensen L. The utility of reporting negative counting values. Radioactivity and Radiochemistry 1991;2:48-56.

26 Altman D. Practical statistics for medical research. London: Chapman and Hall, 1991.

27 Belsley D, Kuh E, Welsch R. Regression diagnostics. New York: Wiley and Sons, 1980

$28 \mathrm{Hu} \mathrm{H}$, Payton M, Korrick S, et al. Determinants of bone and blood lead levels among community-exposed middle-aged to elderly men. Am 7 Epidemiol 1996;144:749-59.

29 Pirkle J, Kaufmann R, Brody D, et al. Exposure of the US population to lead, 1991-4. Environ Health Perspect 998:106:745-50.

30 Schwartz B, Lee B, Stewart W, et al. $\delta$-Aminolevulinic acid dehydratase genotype modifies four hour urinary lead excretion after oral administration of dimercaptosuccinic acid. Occup Environ Med 1997;54:241-6.

$31 \mathrm{Hu} \mathrm{H}$, Milder F, Burger D. $x$ Ray fluorescence measurements of lead burden in subjects with low-level community lead exposure. Arch Environ Health 1990;45:335-41.

32 Kosnett M, Becker C, Osterloh J, et al. Factors influencing bone lead concentration in a suburban community assessed by noninvasive $\mathrm{K} x$ ray fluorescence. $\mathcal{F A M A} 1994 ; 271: 197-$ 203.

33 Hoppin J, Aro $\mathrm{A}, \mathrm{Hu} \mathrm{H}$, et al. In vivo bone lead measurement in suburban teenagers. Pediatrics 1997;100: 365-70.

34 Roy M, Gordon C, Beaumont L, et al. Further experience with bone lead content measurements in residents of southern Ontario. Appl Radiat Isot 1997;48:391-6.

$35 \mathrm{Hu} \mathrm{H}$. Bone lead as a new biologic marker of lead dose: recent findings and implications for public health. Environ Health Perspect 1998;106:961-7.

36 Nilsson U, Attewell R, Christoffersson J-O, et al. Kinetics of lead in bone and blood after the end of occupational exposure. Pharmacol Toxicol 1991;68:477-84.

37 Corey-Slechta D. Mobilization of lead over the course of DMSA chelation therapy and long-term efficacy. $\mathcal{F}$ Pharmacol Exp Ther 1988;246:84-91.

\section{Correspondence and editorials}

Occupational and Environmental Medicine welcomes correspondence relating to any of the material appearing in the journal. Results from preliminary or small scale studies may also be published in the correspondence column if this seems appropriate. Letters should be not more than 500 words in length and contain a minimum of references. Tables and figures should be kept to an absolute minimum. Letters are accepted on the understanding that they be subject to editorial revision and shortening.

The journal also publishes editorials which are normally specially commissioned. The Editor welcomes suggestions regarding suitable topics; those wishing to submit an editorial, however, should do so only after discussion with the Editor. 